\title{
Pelleting Diets Impairs TRAMP Prostate Carcinogenesis
}

\author{
Lauren E. Conlon ${ }^{1}$, Matthew A. Wallig1,2, John W. Erdman1,3* \\ ${ }^{1}$ Division of Nutritional Sciences, University of Illinois at Urbana-Champaign, Urbana, IL, USA \\ ${ }^{2}$ Department of Pathobiology, University of Illinois at Urbana-Champaign, Urbana, IL, USA \\ ${ }^{3}$ Department of Food Science and Human Nutrition, University of Illinois at Urbana-Champaign, Urbana, IL, USA \\ Email: ${ }^{\star}$ lauren.conlon12@gmail.com
}

How to cite this paper: Conlon, L.E., Wallig, M.A. and Erdman, J.W. (2017) Pelleting Diets Impairs TRAMP Prostate Carcinogenesis. Food and Nutrition Sciences, 8, 212-226.

https://doi.org/10.4236/fns.2017.82014

Received: January 17, 2017

Accepted: February 18, 2017

Published: February 21, 2017

Copyright $\odot 2017$ by authors and Scientific Research Publishing Inc. This work is licensed under the Creative Commons Attribution International License (CC BY 4.0).

http://creativecommons.org/licenses/by/4.0/

\section{c) (i) Open Access}

\begin{abstract}
Diets rich in soy products may reduce the risk of prostate cancer (PCa). Daidzein, the major isoflavone present in soy germ, can be metabolized by the gut microbiota into equol. The effects of daidzein and equol on PCa have not been well studied. The objective of this study was to investigate the effect of feeding $2 \%$ soy germ, $92 \mathrm{ppm}$ daidzein, or $88 \mathrm{ppm}$ equol diets on the progression of $\mathrm{PCa}$ in the transgenic adenocarcinoma of the mouse prostate (TRAMP) model. 3-week old male C57BL/6 X FVB TRAMP mice were weaned from our breeding colony and immediately acclimated to an AIN-93G control diet for one week. At 4 weeks of age, mice ( $n=30$ per diet group) were randomized to one of four pelleted study diets until 18 weeks of age. Unexpectedly, we did not detect any statistical differences in cancer incidence between diets. We suggest that these results are due to the physical attributes of the pelleted diets in the current study. Mice fed pelleted diets had reduced food intake and significantly decreased body weights $(\mathrm{p}<0.001)$ compared to previous studies. A reduction in food intake is known to reduce cancer incidence in a number of cancer models and is likely to have contributed to the decrease in expected cancer incidence in the current study. In conclusion, we suggest that the hardness of the diets pellets could result in a decreased cancer incidence in TRAMP mice.
\end{abstract}

\section{Keywords}

Diet, Pelleted, Cancer, Soy, TRAMP

\section{Introduction}

Over the last 30 years, evidence that a diet rich in soy products may be protective against PCa, has been growing. Soy products contain an array of bioactive compounds including saponins, lignans, and the isoflavones genistein, daidzein, and 
glycitein. Intake of isoflavones varies geographically. Consumption of isoflavone-rich foods such as tofu, tempeh, and miso is common in Asian countries where dietary intakes of isoflavones have been estimated to range from $15 \mathrm{mg} /$ day in China to $26-54 \mathrm{mg}$ /day in Japan, while the average intake of isoflavones in Western countries is estimated at $3 \mathrm{mg} /$ day [1] [2].

Our lab recently demonstrated that consumption of a $2 \%$ soy germ diet reduced the incidence of $\mathrm{PCa}$ in the transgenic adenocarcinoma of the mouse prostate (TRAMP) model by $34 \%$ compared to the control diets [3]. Soy germ, the hypocotyl of the soybean, has a radically different isoflavone profile than whole soybeans. It contains considerably higher levels of daidzein and glycitein and relatively low levels of genistein when compared to whole soybeans. Soy germ is currently utilized in dietary supplements, and food scientists have been investigating ways to incorporate it into functional foods for disease prevention [4] [5] [6] [7]. Therefore, it would be beneficial to determine the anticancer effects of soy germ and its mechanisms of action.

Genistein, the predominant isoflavone in soy products, has been investigated for its anti-proliferative, antioxidant, and chemopreventive properties in cell, animal, and human models [8] [9]. Although genistein has been associated with a protection against several cancers and other chronic diseases, there is a need to investigate the effects of other commonly-consumed isoflavones, daidzein, glycitein, and their metabolites.

Epidemiological studies suggest a reduced risk of PCa in men who consume soy products [10], and this effect appears to be especially pronounced in men who are "equol producers" ( $>20 \mathrm{nM}$ serum equol) [11]. Daidzein can be metabolized by the gut microbiota into the weak estrogen-like compound, equol. It is not well understood if equol production is responsible for the protective effect observed with soy intake. Equol has been shown to have a higher binding affinity for estrogen receptor- $\beta(\mathrm{ER} \beta)$ than daidzein [12]. Equol has also been shown in vitro and in vivo to bind $5 \alpha$-dihydroxytestosterone (DHT), thereby inhibiting its binding to the androgen receptor modulating androgen signaling in the prostate [13]. This is significant because equol's ability to be a selective estrogen modulator as well as an androgen antagonist makes it a promising target to study for hormonally-driven cancers like PCa.

In TRAMP mice, we previously demonstrated that prostatic equol was 39 times higher than genistein and 3 times higher than daidzein in mice consuming soy germ [3]. The elevated concentration of equol in the prostate suggests that equol was a critical contributor to the anticarcinogenic effects of soy germ found in the TRAMP model [3]. If the benefits from soy germ are primarily attributed to equol production, then an estimated $70 \%-75 \%$ of the Western population would not benefit from soy germ consumption as it is estimated that only $25 \%$ $30 \%$ of the populations in Western countries are equol "producers" compared to up to $80 \%$ of individuals in China, Japan, and South Korea [14]. Limited in vivo studies have directly examined feeding equol and the incidence of PCa in rodents. Due to the previously observed protective effect of soy germ, we designed 
this study to follow up on the results from Zuniga et al. and compare the effects of soy germ, daidzein, and equol in prostate carcinogenesis [3]. We hypothesized that equol was primarily responsible for the protective effect of soy germ, and that the soy germ, daidzein, and equol-fed mice would have reduced cancer incidence compared to the control group.

\section{Materials and Methods}

\subsection{Animal Methods}

The University of Illinois Laboratory Animal Care Advisory Committee approved all animal procedures. Female and male heterozygous TRAMP (C57BL/6) mice from our colony were bred with $\mathrm{FVB} / \mathrm{NJ}$ mice to obtain $(\mathrm{TRAMP} \times \mathrm{FVB} / \mathrm{NJ}) \mathrm{F}_{1}$ offspring for the study. A minimum of 28 mice per diet group were projected to be needed to reach statistical significance by power analysis $(\alpha=0.05, \beta=0.8$ ) for cancer incidence and two extra mice were added to each diet group to account for the occasional unforeseen death of study animals. Mice were genotyped via PCR-based DNA (Sigma-Aldrich, Saint Louis, MO) screening using established methods [3]. Offspring were weaned at 3 weeks of age, individually housed in shoebox cages under controlled conditions (12 h light/dark cycle, $22^{\circ} \mathrm{C}, 60 \%$ humidity) and acclimated to a pelleted, modified semi-purified AIN-93G diet for one week. The modified AIN-93G included corn oil instead of standard soybean oil as the fat source (Table 1). At 4 weeks of age, mice were

Table 1. Composition of experimental diets.

\begin{tabular}{|c|c|c|c|c|}
\hline \multicolumn{5}{|c|}{$\mathrm{g} / 100 \mathrm{~g}$ total diet } \\
\hline & Control (Modified AIN-93G) & $2 \%$ Soy Germ ${ }^{a}$ & Daidzein $^{\mathrm{b}}$ & Equol $^{\mathrm{C}}$ \\
\hline Cornstarch & 39.7 & 39.8 & 39.7 & 39.7 \\
\hline Casein & 20 & 19 & 20 & 20 \\
\hline Maltodextrin & 13.2 & 13.2 & 13.2 & 13.2 \\
\hline Sucrose & 10 & 10 & 10 & 10 \\
\hline Fiber $^{d}$ & 5 & 4.3 & 5 & 5 \\
\hline Mineral Mix ${ }^{\mathrm{e}}$ & 3.5 & 3.5 & 3.5 & 3.5 \\
\hline Vitamin $\mathrm{Mix}^{\mathrm{f}}$ & 1 & 1 & 1 & 1 \\
\hline L-Cystine & 0.3 & 0.3 & 0.3 & 0.3 \\
\hline Choline Bitrate & 0.25 & 0.25 & 0.25 & 0.25 \\
\hline Corn Oil & 7 & 6.5 & 7 & 7 \\
\hline TBHQ, antioxidant & 0.0014 & 0.0014 & 0.0014 & 0.0014 \\
\hline Soy Germ ${ }^{\mathrm{g}}$ & 0 & 2 & 0 & 0 \\
\hline Daidzein & 0 & 0 & 0.0092 & 0 \\
\hline Equol & 0 & 0 & 0 & 0.0088 \\
\hline
\end{tabular}

a $2 \%$ Soy Germ diet contains $71 \mathrm{ppm}$ daidzein equivalents, $68 \mathrm{ppm}$ glycitein equivalents, and $35 \mathrm{ppm}$ genistein equivalents. ${ }^{b}$ Daidzein diet contains $92 \mathrm{ppm}$ daidzein equivalents. ${ }^{\mathrm{c} E q u o l}$ diet contains $88 \mathrm{ppm}$ equol equivalents. ${ }^{\mathrm{d}}$ Non-nutritive cellulose. ${ }^{\mathrm{e}} \mathrm{AIN}-93 \mathrm{G}-\mathrm{MX}$ formation. ${ }^{\mathrm{f}}$ AIN-93G-VX formation. ${ }^{\mathrm{g}}$ Frutarom SoyLife ${ }^{\circledast}$ Complex Micro. 
randomized to consume one of four experimental diets: AIN-93G control, AIN-93G + 2\% soy germ, AIN-93G + 82 ppm daidzein, or AIN-93G + 88 ppm equol. The daidzein diet included $92 \mathrm{ppm}$ of purified daidzein to match levels found in a $2 \%$ soy germ diet. Equol was matched to daidzein equivalents found in a $2 \%$ soy germ diet with the assumption that $100 \%$ of the daidzein would be metabolized to equol by the highly efficient microbiota in the mouse [15]. Nontransgenic control littermates ( $n=10$ per diet group) were included in the study to confirm the effects of the transgene.

Mice were weighed weekly and individual food intake was measured when fresh food was provided weekly. At 18 weeks of age, mice were asphyxiated by $\mathrm{CO}_{2}$ and blood was collected via cardiac puncture. Serum was separated from the red blood cell volume following centrifugation at $4^{\circ} \mathrm{C}$ for 10 minutes, aliquoted, frozen, and stored at $-80^{\circ} \mathrm{C}$ for future analyses. The prostate was micro-dissected into individual lobes (anterior, ventral, and dorso-lateral). One half of each prostate lobe was fixed overnight in $10 \%$ phosphate-buffered formalin and then transferred to $70 \%$ ethanol for histological evaluation. All animals were thoroughly examined for gross metastases by trained research staff during the necropsy. A section of liver, lungs, and lymph nodes were fixed in $10 \%$ phosphate-buffered formalin and transferred to $70 \%$ ethanol after 24 hours for evaluation of micro-metastases. Liver, testes, spleen, gonadal adipose, and one half of each prostate lobe were flash frozen in liquid nitrogen and stored at $-80^{\circ} \mathrm{C}$.

\subsection{Diet Formulation and Isoflavone Analysis}

Experimental diets were pelleted and prepared as a custom AIN-93G formulation by Harlan Laboratories (Madison, WI). Diets were balanced for protein, carbohydrates, fat, energy, and fiber, provided $3.8 \mathrm{Kcal} / \mathrm{g}$, and were stored at $4^{\circ} \mathrm{C}$ in the dark. Experimental diet compositions are presented in Table 1. Diets were pelleted to ensure proper mixing and distribution of the soy germ, daidzein, and equol. Soy germ was analyzed for daidzein isoflavone equivalents. Isoflavone contents of the final experimental diets were analyzed by the National Center for Toxicological Research in Jefferson, AR using HPLC-UV. Briefly, $500 \mathrm{mg}$ of diet was crushed and ground into a powder and placed in a $15 \mathrm{~mL}$ centrifuge tube. $2.5 \mathrm{~mL}$ of $80 \%$ methanol:water $(80: 20, \mathrm{v} / \mathrm{v})$ was added to each tube. Samples were vortexed and then sonicated for 30 minutes. The supernatant was removed following centrifugation and placed into a $10 \mathrm{~mL}$ volumetric flask. The above methanol:water addition, vortex, sonication, and centrifugation was performed 3 5 more times and the supernatants were combined for each sample. The combined supernatant was filtered prior to HPLC analysis. Isoflavone analysis of prepared diets is presented in Table 2.

\subsection{Serum Isoflavone Analysis}

Serum isoflavones were analyzed by the National Center for Toxicological Research in Jefferson, AR using HPLC-UV [16]. The limits of detection of genistein, daidzein, and equol were $0.004,0.002$, and $0.03 \mu \mathrm{M}$ respectively. 
Table 2. Isoflavone analyses of the prepared diet (ppm).

\begin{tabular}{cccc}
\hline Diet & $\begin{array}{c}\text { AIN-93G + 2\% Soy Germ } \\
(\mathrm{ppm})\end{array}$ & $\begin{array}{c}\text { AIN-93G + 92 ppm Daidzein } \\
(\mathrm{ppm})\end{array}$ & $\begin{array}{c}\text { AIN-93G + 88 ppm Equol } \\
(\mathrm{ppm})\end{array}$ \\
\hline Genistein & 35 & 0 & 0 \\
Daidzein & 71 & 90 & 0 \\
Glycitein & 68 & 0 & 0 \\
Equol & 0 & 0 & 80 \\
\hline
\end{tabular}

Table 2 shows the isoflavone analyses in the diets. Genistein, daidzein, glycitein, and equol were detected in the soy germ diet. Only daidzein and equol were detected in their respective diets. Values are the mean of $\mathrm{n}=5$.

\subsection{Histopathology}

Formalin-fixed, paraffin-embedded prostate sections were stained with hematoxylin and eosin (H\&E) and blindly evaluated by a pathologist using an established and published grading scheme [17]. Each lobe of the prostate was evaluated for the most severe lesion and the most common lesion in each lobe. Additionally, sections of liver and lungs from mice with gross tumors and visible lymph node metastases were evaluated for the presence of micro-metastases. Results were compared using Fisher's exact test between treatment groups and the control.

\subsection{Immunohistochemistry}

Immunohistochemistry for proliferating cell nuclear antigen (PCNA) and cleaved caspase-3 (CC3) were performed on paraffin-embedded $(4 \mu \mathrm{m})$ fixed sections of the dorso-lateral prostate lobe according to a previously published protocols [18] [19]. Briefly, slides were placed in a decloaking chamber and treated in a citrate buffer ( $\mathrm{pH}$ 6.0) for 30 seconds at $125^{\circ} \mathrm{C}$ and 10 seconds at $90^{\circ} \mathrm{C}$ for antigen retrieval. In a BioGenex i6000 Automated Staining System (BioGenex, San Ramon, CA), endogenous peroxide was quenched with a $3 \%$ $\mathrm{H}_{2} \mathrm{O}_{2}$ solution for 15 minutes, slides were blocked with Power Block ${ }^{\mathrm{TM}}$ (BioGenex) for 10 minutes, avidin blocked for 15 minutes, and then incubated with rabbit anti-proliferating cell nuclear antigen (PCNA) antibody (Abcam, Cambridge, MA) or rabbit anti-cleaved caspase-3 (Cell Signaling, Danvers, MA) for 30 minutes and visualized using a Super Sensitive ${ }^{\mathrm{TM}}$ Link-Label IHC Detection System (BioGenex). Slides were stained with $\mathrm{DAB}$ and counterstained with hematoxylin. Mouse small intestinal tissue was used as the positive control for PCNA and mouse thymus tissue was used as the positive control for cleaved caspase-3. Negative controls were generated by omitting the primary antibody. Stained slides were scanned with a NanoZoomer 2.0-HT digital slide scanner (Hamamatsu, Bridgewater, NJ) with Olympus Uplansapo $20 \times$ objective at $40 \mathrm{X}$ digital zoom, resulting in $0.23 \mu \mathrm{m}$ resolution. Images were captured with NDP view software (Hamamatsu). One image from the dorso-lateral lobe was blindly quantified and the proliferative index (PI) percentage (PCNA positive-stained nuclei/total nuclei counted $\times 100$ ) and apoptotic index (AI) percentage (number of activated caspase- 3 cells/otal nuclei counted $\times 100$ ) calculated. These indices 
were established by counting at least 1000 randomly selected cells from each image.

\subsection{Serum Testosterone}

Serum testosterone was measured in TRAMP mice fed control $(\mathrm{n}=10)$, soy germ $(n=10)$, daidzein $(n=10)$, and equol $(n=10)$ diets. Serum testosterone was extracted from $150 \mu \mathrm{L}$ of serum using di-ethyl ether. After the ether evaporated, a hexane and methanol extraction was used to extract the testosterone from other serum lipids for analyses. Serum testosterone was evaluated using Coat-A-Count total testosterone radioimmunoassay (Siemens TKTT2, Los Angeles, CA).

\subsection{Statistical Analyses}

Statistical analyses were completed with SAS software (version 9.2; SAS Institute, Cary, NC, USA). Body weight, food intake, serum isoflavones, serum, testosterone, and proliferation and apoptosis indexes were compared among treatments by analysis of variance (ANOVA) when the assumptions of ANOVA were met, and followed by post-hoc Tukey-Kramers studentized range test with $\alpha=0.05$; when the assumptions of ANOVA were not met, the Wilcoxon and KruskalWallis non-parametric test was chosen. Differences in cancer incidence by histopathology and diet group were analyzed using Fisher's exact test.

\section{Results}

\subsection{Weight Gain and Feed Intake}

Body weight and food intake were measured weekly and recorded. Food intake was not significantly different between groups (Table 3). Average food intake was similar to other studies of TRAMP mice consuming pelleted diets [20] [21], but $50 \%$ less than powdered diets fed by Zuniga et al. [3]. Body weights were not significantly different between groups. Organ weights of the urogenital tract, liver, lungs, testes, gonadal adipose, spleen, ventral prostate, anterior prostate, and dorso-lateral prostate were not different between groups (data not shown).

Table 3. TRAMP body weights and food intake.

\begin{tabular}{ccccc}
\hline & $\begin{array}{c}\text { AIN-93G } \\
\text { Control }\end{array}$ & $\begin{array}{c}\text { AIN-93G }+2 \% \text { Soy } \\
\text { Germ }\end{array}$ & $\begin{array}{c}\text { AIN-93G + 92 ppm } \\
\text { Daidzein }\end{array}$ & $\begin{array}{c}\text { AIN-93G + 88 ppm } \\
\text { Equol }\end{array}$ \\
\hline $\begin{array}{c}\text { Beginning Body } \\
\text { Weight (g) }\end{array}$ & $20.2 \pm 3.7$ & $19.4 \pm 3.6$ & $20.3 \pm 3.8$ & $20.6 \pm 3.8$ \\
$\begin{array}{c}\text { Ending Body Weight } \\
\text { (g) }\end{array}$ & $27.3 \pm 5$ & $27 \pm 5$ & $27.7 \pm 5$ & $28 \pm 5$ \\
$\begin{array}{c}\text { Average Food Intake } \\
\text { (g/day) }\end{array}$ & $2.3 \pm 0.4$ & $2.3 \pm 0.4$ & $2.3 \pm 0.4$ & $2.2 \pm 0.4$ \\
$\mathrm{n}$ & 30 & 29 & 30 & 30 \\
\hline
\end{tabular}

Table 3 shows that there is no difference between body weights and food intakes between diet groups in this study. Values are the mean \pm SEM. 


\subsection{Serum Isoflavones}

Genistein, daidzein, and equol were below the limit of detection in the AIN-93G control-fed mice. Genistein was only detected in mice consuming soy germ. Daidzein was only detected in the serum of mice fed soy germ or the daidzein diet and was significantly different between the two groups $(\mathrm{p}=0.048)$ (Table 4). Equol was detected in all the mouse serums from experimental diet groups except for the control diet and was not statistically different between groups. Differences in serum isoflavones between diets were analyzed using ANOVA and the Tukey-Kramer studentized range test $(\alpha=0.05)$.

\subsection{Histopathology}

There were no differences in overall combined cancer incidence between diet groups (Figure 1). Mice fed the control, soy germ, daidzein, and equol diets had a $24 \%, 31 \%, 20 \%$, and $28 \%$ incidence of cancer overall respectively. There was also no difference in cancer incidence by diet between anterior, ventral, or dorso-lateral lobes individually (data not shown). Furthermore, we were not able to detect any differences between pathology scores between diet groups (Table 5).

Table 4. TRAMP serum isoflavone analyses.

\begin{tabular}{|c|c|c|c|c|}
\hline \multicolumn{5}{|c|}{ Serum $(\mu \mathrm{M})$} \\
\hline Diet & Control & $2 \%$ Soy Germ & Daidzein & Equol \\
\hline Genistein & ND & $0.11 \pm 0.05$ & ND & ND \\
\hline Daidzein & ND & $0.44 \pm 0.27^{\mathrm{a}}$ & $0.17 \pm 0.18^{\mathrm{b}}$ & ND \\
\hline Equol & ND & $2.67 \pm 1.92$ & $1.44 \pm 0.46$ & $3.37 \pm 2.12$ \\
\hline
\end{tabular}

Table 4 shows serum levels of isoflavones between diet groups. A significant difference was found in the level of serum daidzein between the soy germ-fed and the daidzein-fed groups. Values are Mean \pm SEM. $\mathrm{ND}=$ Not detected in the serum. Superscript letters in the same row indicate a significant difference between groups $(\mathrm{p}=0.048) . \mathrm{n}=7$ per group.

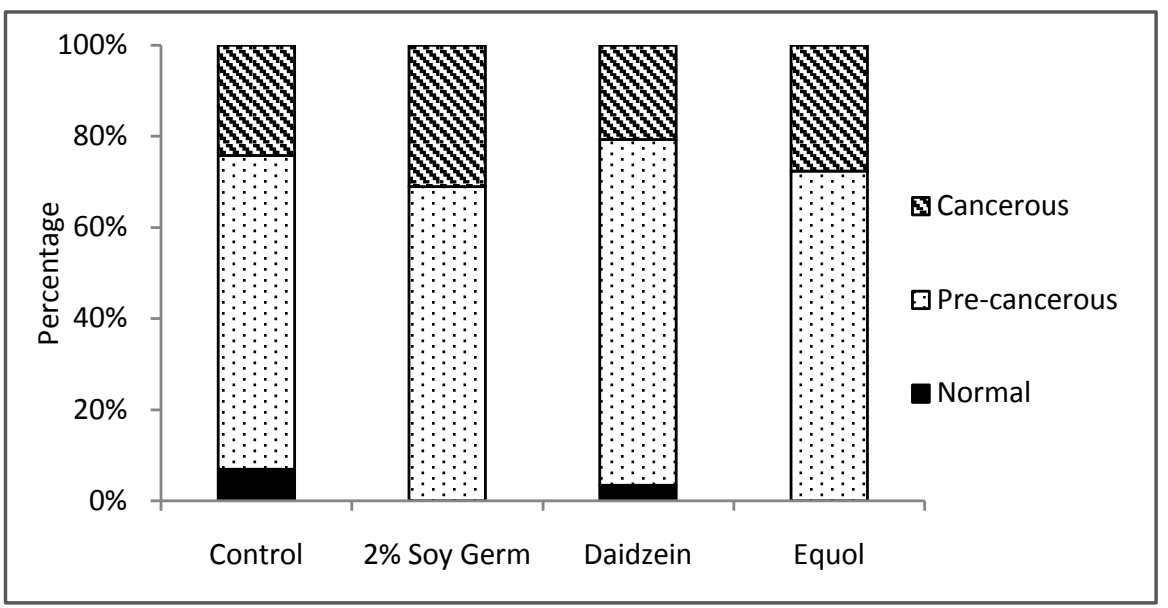

Figure 1. Overall prostate cancer incidence in TRAMP mice. (In Figure 1, different patterned bars represent the distribution of cancer severity among diets. No differences were present between the experimental diets and the control or between experimental diets. $\mathrm{n}=$ 29 - 30/diet group). 


\subsection{Immunohistochemistry}

There was no statistical difference between AI (Figure 2) or PI (Figure 3) between diet groups in prostates with HGP.

\subsection{Serum Testosterone}

There were no statistical differences in serum testosterone levels between groups (Figure 4). Furthermore, we examined serum testosterone levels in wild-type non-transgenic mice $(n=5 /$ diet $)$ to determine the impact of our diets on serum testosterone in a non-cancer model. There were no differences between groups, though the daidzein group was numerically lower than the other diet groups (Figure 5).

\section{Discussion}

Due to previous findings in our laboratory [3], we hypothesized that diets incorporating $2 \%$ soy germ, daidzein, or equol would equally reduce the incidence

Table 5. TRAMP histopathology results as a percentage of total prostatic lesions by diet results are the incidence of each stage of pathology and overall incidence (sum of WDPD) within dietary groups.

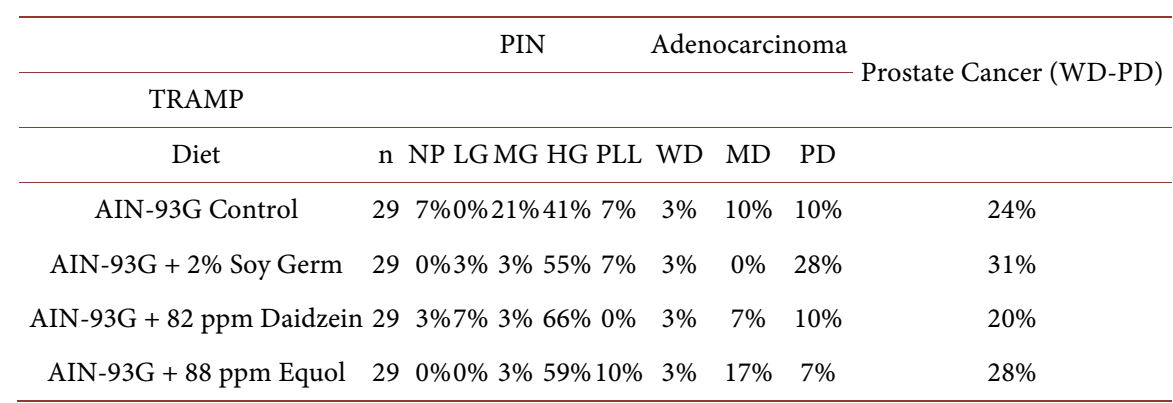

$\mathrm{NP}=$ Normal Prostate, $\mathrm{LG}=$ low grade PIN, $\mathrm{MG}=$ moderate grade PIN, $\mathrm{HG}=$ high-grade PIN, $\mathrm{PLL}=$ phyllode-like lesions, $\mathrm{WD}=$ well differentiated, $\mathrm{MD}=$ moderately differentiated, $\mathrm{PD}=$ poorly differentiated.

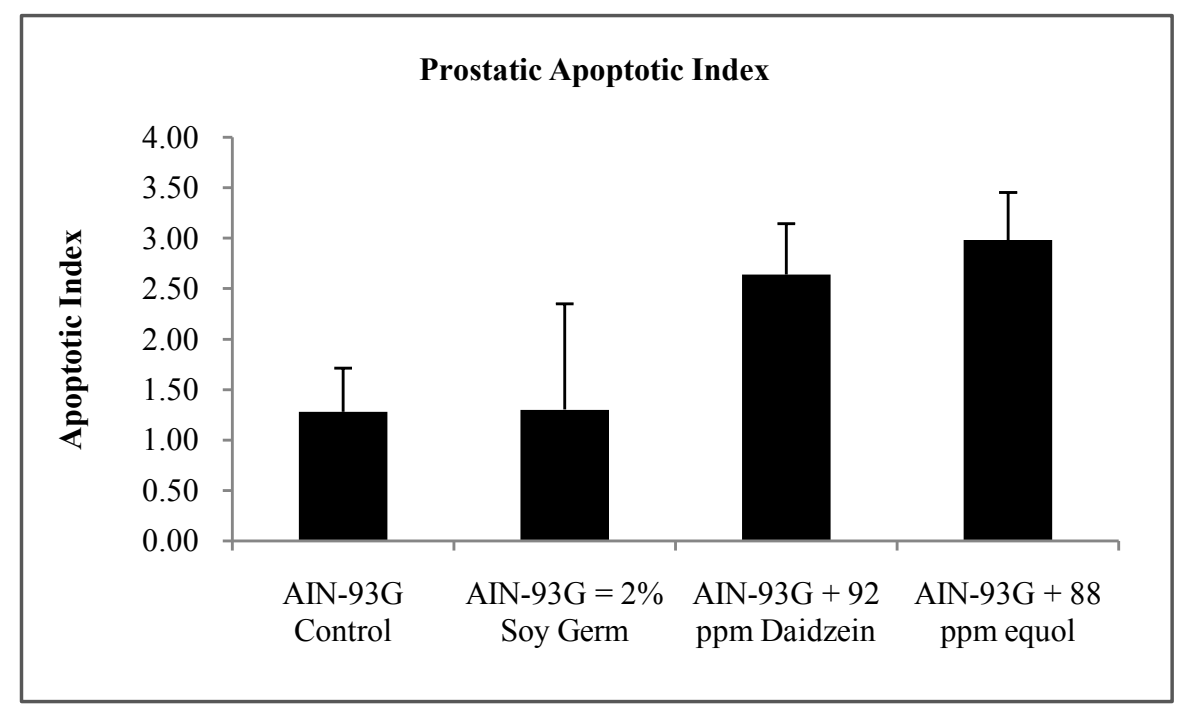

Figure 2. TRAMP prostatic apoptotic index. (Values are means \pm SEM. $n=5 /$ diet groups). 


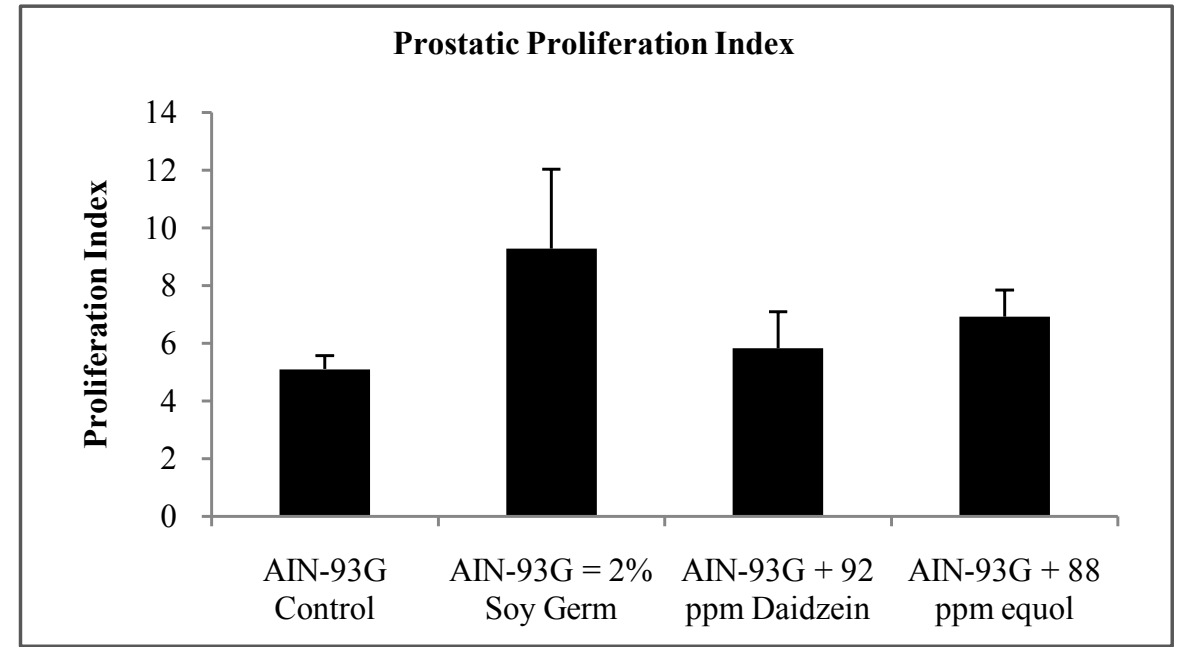

Figure 3. TRAMP proliferation index. (Values are means \pm SEM. $n=5 /$ diet group).

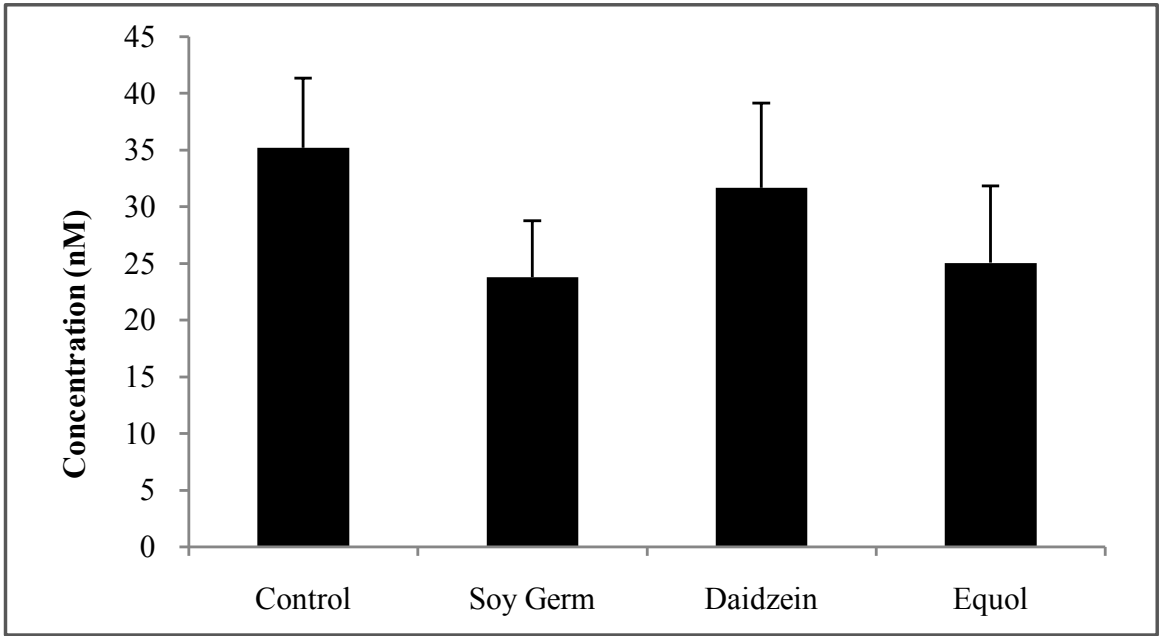

Figure 4. TRAMP serum testosterone. (Figure 4 shows serum levels of testosterone in TRAMP mice. There were no significant differences detected between diet groups. Values represent mean \pm SEM. $\mathrm{n}=10$ /diet group).

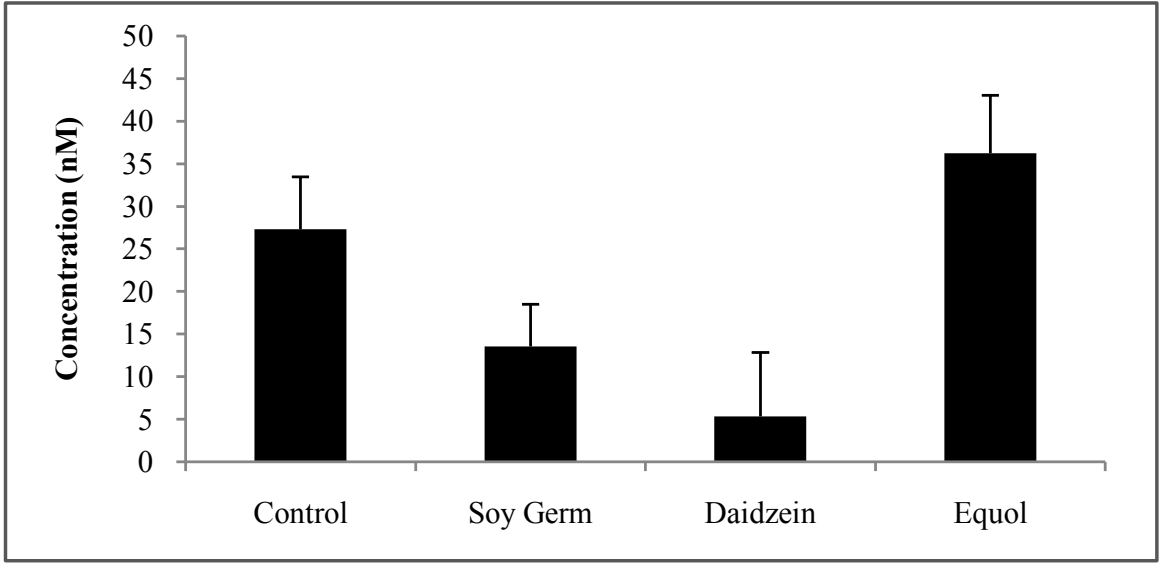

Figure 5. Wild-type serum testosterone. (Figure 5 shows serum levels of testosterone in wild-type mice. There were no significant differences detected between diet groups. Values represent mean \pm SEM. $n=10$ /diet group). 
of PCa in TRAMP mice compared to the control diet. We further hypothesized that the mechanism would be due to the isoflavone metabolite, equol. Contrary to our hypothesis, we did not detect any dietary differences in cancer incidence. Mice in the control group only had a $24 \%$ incidence of cancer whereas in a previous study in our lab, mice in the control group had a $100 \%$ incidence of cancer at the same 18-week time point [3]. Despite using the same animal model, rodent colony, animal facility, sacrifice age, lot of soy germ, and animal procedures, we were not able to repeat the previous findings [3]. Similar levels of isoflavones were detected in the serum and diets from both studies. The only difference, aside from specific diets used, was the physical format that the diet was provided to the rodents. Zuniga et al. fed rodents a powdered version of the AIN-93G-based diets, while the current study provided the similarly-formulated diets in pelleted form [3].

The diet's physical form resulted in drastically different food intakes between the studies. Zuniga et al. reported that mice consumed 5.7 grams/day while in the current study only 2.3 grams/day were consumed [3]. It should be noted that measurement of powdered food intake is less precise than with pelleted food intake, as powdered food tends to be distributed in bedding and in the cage, so at best, we can only get an estimate of powdered food intake in these studies. Nonetheless, pelleted food intake in the current study was consistent with other studies of TRAMP mice consuming pelleted diets [20] [21]. The differences in food intake resulted in significantly different body weights between the two studies (Figure 6). Mice fed pelleted diets in the current study were significantly lighter than mice fed powdered diets in the previous study as early as 8 weeks of age $(\mathrm{p}<$ 0.001 ) and continuing until animals were sacrificed at 18 weeks of age (Figure 6) $(\mathrm{p}<0.001)$.

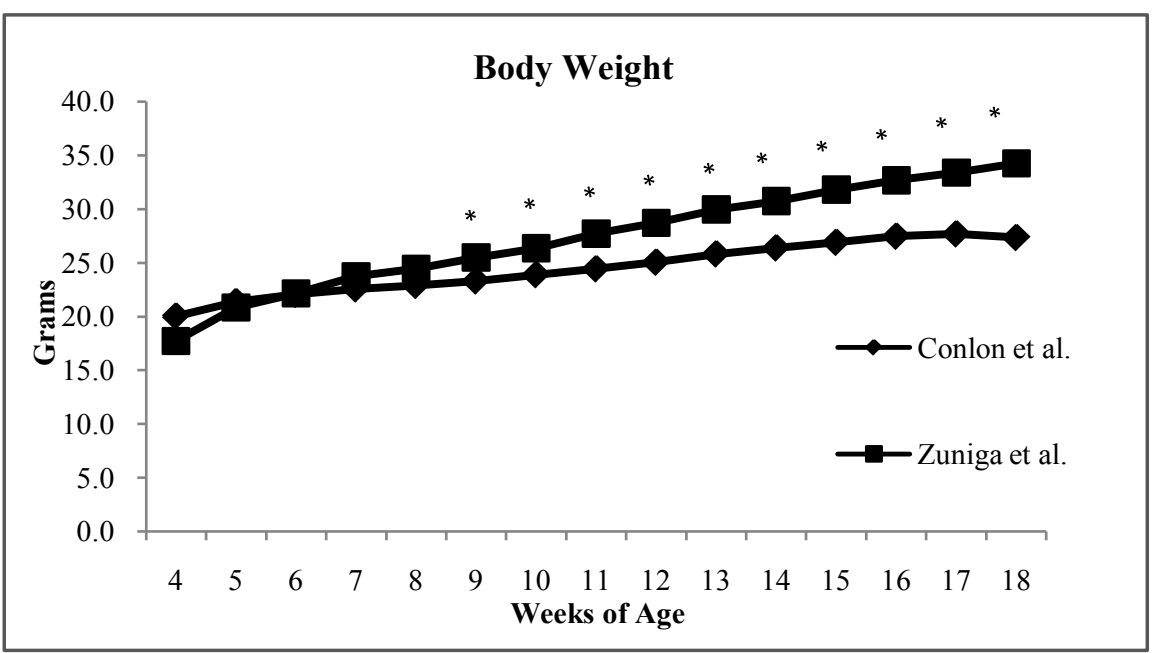

Figure 6. TRAMP body weight comparison between Zuniga et al. and Conlon et al. (Figure 6 is a graphical representation of body weights between the current study and a previous study by Zuniga et al. [3]. ${ }^{*}$ Represents a significant difference $(\alpha<0.05)$ between Zuniga et al. and the current study, Conlon et al. at specific time points. Values represent the mean body weight across all diets at each week of age. Both studies $n=29-31$ were weighed at each time point). 
The associations between diet format and obesity have been examined extensively in rodent models [22] [23] [24]. Ford et al. described the association between food consumption and diet hardness in mice, and observed that increasing the hardness of food, negatively impacted growth and food intake [25]. Additionally, rats fed soft pellets developed obesity faster than their counterparts fed hard pellets [26]. Desmarchelier et al. examined the impact of feeding a control, high-fat, and Western diet to mice in either pelleted or powdered form [24]. The results of that study indicated that regardless of diet composition, all mice fed powdered diets had similar weight gains [24]. This suggests that the texture and hardness of the food, rather than the nutrient composition, promoted hyperphagia and obesity [24]. Furthermore, in another study, long-term ingestion of powdered food induced hyperglycemia and systemic illness, increased adrenal gland activity, and increased blood pressure in mice [22]. This could be a result of easier access to powdered foods (bowls of food in the cage vs. food provided above the cage in a rack), ingestion of powdered food from fur while cleaning, and/or faster rates of absorption of powdered food [22]. Together these findings suggest that the dietary format of food impacts the growth, development, and systemic health of healthy rodents. A diet in powdered format that contributes to excessive weight gain and systemic illness may promote carcinogenesis in a transgenic mouse model of PCa while pelleted diets might delay the onset of carcinogenesis.

It has been previously shown that TRAMP mice fed a high-fat Western diet have accelerated tumor growth and tumor burden compared to the control-fed mice [27]. Alternatively, caloric restriction has been shown to reduce PCa incidence and progression in TRAMP mice [20] [28]. A 20\% dietary restriction beginning at 7 weeks of age resulted in significant reductions in PCa incidence at 11 and 20 weeks of age in TRAMP mice [29]. Additionally, TRAMP mice who were intermittently or chronically calorically restricted had a decreased incidence of PCa [20]. While in the current study, the mice were not purposely calorically restricted and were allowed access to their food ad libitum, they consumed nearly $50 \%$ fewer grams of food/day than mice fed powdered food and weighed significantly less than mice fed powdered food [3]. This reduction in food intake most likely accounted for the reduction in cancer incidence observed.

However, changes in caloric intake and energy balance and expenditure also alters cancer incidence in TRAMP mice. While caloric restriction alone has been shown to reduce cancer incidence in the TRAMP model, changes in energy balance and excess caloric retention contribute to cancer progression. Mice housed at $22^{\circ} \mathrm{C}$ expend more energy and have lower body mass than mice housed closer to their thermoneutral zone $\left(30^{\circ} \mathrm{C}-35^{\circ} \mathrm{C}\right)$ [30]. Interestingly, when mice are housed a $22^{\circ} \mathrm{C}$, they consume $30 \%$ more calories, but have less body mass than mice housed at $27^{\circ} \mathrm{C}$ [30]. This suggests that mice consume more food to compensate for thermoregulatory demands, but that energy balance plays a role beyond food intake. The use of pelleted diets in the current study and the tem- 
perature mice were housed at $\left(22^{\circ} \mathrm{C}\right)$ combined to produce an environment where mice had to expend energy to consume food (standing/reaching for pellets) and expend energy to maintain thermoregulation, ultimately keeping their body weight lower. Mice in prior studies in our lab fed powdered diets slept in their food bowls, consumed diet when grooming, and ultimately gained more body weight than mice in the current study [3]. These results suggest that pelleted diets fed ad libitum resulted in decreased body weight and decreased cancer incidence compared to mice fed powdered diets ad libitum [3]. The decrease in body weight was likely a contributing factor to the decrease in expected cancer incidence in all dietary treatment groups.

In this study, cancer incidence was remarkably lower in the TRAMP model than previous studies in our lab [3] [31]. The reduction in cancer incidence may be explained by a change in dietary format from powdered to pelleted diets. The combination of feeding pelleted diets and housing mice individually below their thermonuetral zone may have shifted energy balance in TRAMP mice to only eat enough for maintenance and growth. Future studies utilizing pelleted diets might detect differences between dietary treatments by prolonging the sacrifice age further than 18 weeks to allow for cancer development or switching back to powdered diets. Despite null results regarding cancer incidence, we observed a significant effect of daidzein and equol on serum cytokines in mice with prostate tumors. This may suggest that daidzein and equol diets, but not a whole soy germ diet, may have anti-inflammatory properties in advanced stage PCa. Future studies in TRAMP mice should examine serum cytokine levels as well as prostatic and tumoral mRNA expression of cytokines to confirm these findings.

\section{Acknowledgements}

The authors would like to thank Frutarom for donation of the soy germ powder and Dr. William Helferich for the donation of the purified daidzein and equol. We would also like to thank Dr. Smille and Dr. Wang at the University of Mississippi for analyzing the soy germ, daidzein, and equol and Dr. Doerge at the FDA's National Center for Toxicological Research for analyzing serum and diet isoflavones. This work was supported by National Institutes of Health P50 AT006265.

\section{References}

[1] Pudenz, M., Roth, K. and Gerhauser, C. (2014) Impact of Soy Isoflavones on the Epigenome in Cancer Prevention. Nutrients, 6, 4218-4272.

https://doi.org/10.3390/nu6104218

[2] Messina, M., Nagata, C. and Wu, A.H. (2006) Estimated Asian Adult Soy Protein and Isoflavone Intakes. Nutrition and Cancer, 55, 1-12.

https://doi.org/10.1207/s15327914nc5501_1

[3] Zuniga, K.E., Clinton, S.K. and Erdman, J.W. (2013) The Interactions of Dietary Tomato Powder and Soy Germ on Prostate Carcinogenesis in the TRAMP Model. Cancer Prevention Research, 6, 548-557.

https://doi.org/10.1158/1940-6207.CAPR-12-0443 
[4] Bohn, T., Blackwood, M., Francis, D., Tian, Q., Schwartz, S.J. and Clinton, S.K. (2013) Bioavailability of Phytochemical Constituents from a Novel Soy Fortified Lycopene Rich Tomato Juice Developed for Targeted Cancer Prevention Trials. Nutrition and Cancer, 65, 919-929. https://doi.org/10.1080/01635581.2011.630156

[5] Setchell, K.D.R., Nardi, E., Battezzati, P.M., Asciutti, S., Castellani, D., Perriello, G. and Clerici, C. (2013) Novel Soy Germ Pasta Enriched in Isoflavones Ameli-orates Gastroparesis in Type 2 Diabetes: A Pilot Study. Diabetes Care, 36, 3495-3497. https://doi.org/10.2337/dc12-1615

[6] Clerici, C., Nardi, E., Battezzati, P.M., Asciutti, S., Castellani, D., Corazzi, N., Giuliano, V., Gizzi, S., Perriello, G., Di Matteo, G., Galli, F. and Setchell, K.D. (2011) Novel Soy Germ Pasta Improves Endothelial Function, Blood Pressure, and Oxidative Stress in Patients with Type 2 Diabetes. Diabetes Care, 34, 1946-1948. https://doi.org/10.2337/dc11-0495

[7] Tiziani, S. and Vodovotz, Y. (2005) Rheological Characterization of a Novel Functional Food: Tomato Juice with Soy Germ. Journal of Agricultural and Food Chemistry, 53, 7267-7273. https://doi.org/10.1021/jf0511087

[8] Ahmad, A., Biersack, B., Li, Y., Bao, B., Kong, D., Ali, S., Banerjee, S. and Sarkar, F.H. (2013) Perspectives on the Role of Isoflavones in Prostate Cancer. AAPS Journal, 15, 991-1000. https://doi.org/10.1208/s12248-013-9507-1

[9] Mahmoud, A.M., Yang, W. and Bosland, M.C. (2014) Soy Isoflavones and Prostate Cancer: A Review of Molecular Mechanisms. Journal of Steroid Biochemistry and Molecular Biology, 140, 116-132. https://doi.org/10.1016/j.jsbmb.2013.12.010

[10] Sugiyama, Y., Masumori, N., Fukuta, F., Yoneta, A., Hida, T., Yamashita, T., Minatoya, M., Nagata, Y., Mori, M. Tsuji, H., Akaza, H. and Tsukamoto, T. (2013) Influence of Isoflavone Intake and Equol-Producing Intestinal Flora on Prostate Cancer Risk. Asian Pacific Journal of Cancer Prevention, 14, 1-4. https://doi.org/10.7314/APJCP.2013.14.1.1

[11] Akaza, H., Miyanaga, N., Takashima, N., Naito, S., Hirao, Y., Tsukamoto, T., Fujioka, T., Mori, M. Kim, W.J., Song, J.M. and Pantuck, A.J. (2004) Comparisons of Percent Equol Producers between Prostate Cancer Patients and Controls: CaseCon-Trolled Studies of Isoflavones in Japanese, Korean and American Residents. Japanese Journal of Clinical Oncology, 34, 86-89. https://doi.org/10.1093/jjco/hyh015

[12] Atkinson, C., Frankenfeld, C.L. and Lampe, J.W. (2005) Gut Bacterial Metabolism of the Soy Isoflavone Daidzein: Exploring the Relevance to Human Health. Experimental Biology and Medicine, 230, 155-170.

[13] Lund, T.D., Munson, D.J., Haldy, M.E., Setchell, K.D.R., Lephart, E.D. and Handa, R.J. (2004) Equol Is a Novel Anti-Androgen That Inhibits Prostate Growth and Hormone Feedback. Biology of Reproduction, 70, 1188-1195.

https://doi.org/10.1095/biolreprod.103.023713

[14] Setchell, K.D.R. and Clerici, C. (2010) Equol: History, Chemistry, and Formation. Journal of Nutrition, 3, 1355-1362. https://doi.org/10.3945/jn.109.119776

[15] Setchell, K.D.R., Brown, N.M. and Lydeking-Olsen, E. (2002) The Clinical Importance of the Metabolite Equol-A Clue to the Effectiveness of Soy and its Isoflavones. Journal of Nutrition, 132, 3577-3584.

[16] Griffith, A.P. and Collison, M.W. (2001) Improved Methods for the Extraction and Analysis of Isoflavones from Soy-Containing Foods and Nutritional Supplements by Reverse-Phase High-Performance Liquid Chromoatography and Liquid Chromatography-Mass Spectrometry. Journal of Chromatography A, 913, 397-413. https://doi.org/10.1016/S0021-9673(00)01077-3 
[17] Berman-Booty, L.D., Sargeant, A.M., Rosol, T.J., Rengel, R.C., Clinton, S.K., Chen, C.S. and Kulp, S.K. (2012) A Review of the Existing Grading Schemes and a Proposal for a Modified Grading Scheme for Prostatic Lesions in TRAMP Mice. Toxicologic Pathology, 40, 5-17. https://doi.org/10.1177/0192623311425062

[18] Gown, A.M. and Willingham, M.C. (2002) Improved Detection of Apoptotic Cells in Archival Paraffin Sections: Immunohistochemistry Using Antibodies to Cleaved Caspase 3. Journal of Histochemistry and Cytochemistry, 50, 449-454. https://doi.org/10.1177/002215540205000401

[19] Liao, Z., Boileau, T.W., Erdman, J.W. and Clinton, S.K. (2002) Interrelationships among Angiogenesis, Proliferation, and Apoptosis in the Tumor Microenvironment During $N$-Methyl- $N$-Nitrosourea Androgen-Induced Prostate Carcinogenesis in Rats. Carcinogenesis, 23, 1701-1711. https://doi.org/10.1093/carcin/23.10.1701

[20] Bonorden, M.J., Rogozina, O.P., Kluczny, C.M., Grossmann, M.E., Grambsch, P.L., Grande, J.P., Perkins, S., Lokshin, A. and Cleary, M.P. (2009) Intermittent Calorie Restriction Delays Prostate Tumor Detection and Increases Survival Time in TRAMP Mice. Nutrition and Cancer, 61, 265-275. https://doi.org/10.1080/01635580802419798

[21] Prasad, A.S., Mukhtar, H., Beck, F.W., Adhami, V.M., Siddiqui, I.A., Din, M., Hafeez, B.B. and Kucuk, O. (2010) Dietary Zinc and Prostate Cancer in the TRAMP Mouse Model. Journal of Medicinal Food, 13, 70-76. https://doi.org/10.1089/jmf.2009.0042

[22] Tsuchiya, M., Niijima-Yaoita, F., Yoneda, H., Chiba, K., Tsuchiya, S., Hagiwara, Y., Sasaki, K., Sugawara, S., Endo, Y., Tan-No, K. and Watanabe, M. (2014) Long-Term Feeding on Powdered Food Causes Hyperglycemia and Signs of Systemic Illness in Mice. Life Sciences, 103, 8-14. https://doi.org/10.1016/j.lfs.2014.03.022

[23] Ramirez, I. and Friedman, M.I. (1990) Dietary Hyperphagia in Rats: Role of Fat, Carbohydrate, and Energy Content. Physiology \& Behavior, 47, 1157-1163. https://doi.org/10.1016/0031-9384(90)90367-D

[24] Desmarchelier, C., Ludwig, T., Scheundel, R., Rink, N., Bader, B.L., Klingenspor, M. and Daniel, H. (2013) Diet-Induced Obesity in Ad Libitum-Fed Mice: Food Texture Overrides the Effect of Macronutrient Composition. British Journal of Nutrition, 109, 1518-1527. https://doi.org/10.1017/S0007114512003340

[25] Ford, D.J. (1977) Influence of Diet Pellet Hardness and Particle Size on Food Utilization by Mice, Rats and Hamsters. Laboratory Animals, 11, 241-246.

https://doi.org/10.1258/002367777780936486

[26] Oka, K., Sakuarae, A., Fujise, T., Yoshimatsu, H., Sakata, T. and Nakata, M. (2003) Food Texture Differences Affect Energy Metabolism in Rats. Journal of Dental Research, 82, 491-494. https://doi.org/10.1177/154405910308200617

[27] Llaverias, G., Danilo, C., Wang, Y., Witkiewicz, A.K., Daumer, K., Lisanti, M.P. and Frank, P.G. (2010) A Western-Type Diet Accelerates Tumor Progression in an Autochthonous Mouse Model of Prostate Cancer. American Journal of Pathology, 177, 3180-3191. https://doi.org/10.2353/ajpath.2010.100568

[28] Suttie, A.W., Dinse, G.E., Nyska, A., Moser, G.J., Goldsworthy, T.L. and Maronpot, R.R. (2005) An Investigation of the Effects of Late-Onset Dietary Restriction on Prostate Cancer Development in the TRAMP Mouse. Toxicologic Pathology, 33, 386-397. https://doi.org/10.1080/01926230590930272

[29] Suttie, A., Nyska, A., Haseman, J.K., Moser, G.J., Hackett, T.R. and Goldsworthy, T.L. (2003) A Grading Scheme for the Assessment of Proliferative Lesions of the Mouse Prostate in the TRAMP Model. Toxicologic Pathology, 31, 31-38. https://doi.org/10.1080/01926230390173842 
[30] Huffman, D.M., Johnson, M.S., Watts, A., Elgavish, A., Eltoum, I.A. and Nagy, T.R. (2007) Cancer Progression in the Transgenic Adenocarcinoma of Mouse Prostate Mouse Is Related to Energy Balance, Body Mass, and Body Composition, but notFood Intake. Cancer Research, 67, 417-424. https://doi.org/10.1158/0008-5472.CAN-06-1244

[31] Liu, A.G., Juvik, J.A., Jeffery, E.H., Berman-Booty, L.D., Clinton, S.K. and Erdman, J.W. (2014) Enhancement of Broccoli Indole Glucosinolates by Methyl Jasmonate Treatment and Effects on Prostate Carcinogenesis. Journal of Medicinal Food, 17, 1177-1182. https://doi.org/10.1089/jmf.2013.0145

\section{Scientific Research Publishing}

Submit or recommend next manuscript to SCIRP and we will provide best service for you:

Accepting pre-submission inquiries through Email, Facebook, LinkedIn, Twitter, etc. A wide selection of journals (inclusive of 9 subjects, more than 200 journals)

Providing 24-hour high-quality service

User-friendly online submission system

Fair and swift peer-review system

Efficient typesetting and proofreading procedure

Display of the result of downloads and visits, as well as the number of cited articles Maximum dissemination of your research work

Submit your manuscript at: http://papersubmission.scirp.org/

Or contact fns@scirp.org 